\title{
THE ROLES OF INFORMAL INTERNET TOOLS IN SUPPORTING FORMAL LEARNING IN SAUDI ARABIAN UNIVERSITIES
}

\author{
Abdullah Alenezi \\ Northern Borders University, Arar, Saudi Arabia
}

\begin{abstract}
The study explores the applications of informal Internet tools on improving the learning outcomes, academic achievements and career advancement of the Saudi Arabian university students. A systematic review of studies conducted on various institutions of higher learning across Saudi Arabia enabled the researcher to evaluate the trends in the use of informal digital learning tools. The paper pools evidences from multiple studies of similar design to examine the strengths, weaknesses and gaps in the applications of digital technology in improving the learning outcomes, skills and knowledge acquisition among the university students.The internet tools present the best platform for reflective practice, exhaustive knowledge sharing, skills upgrade and accessing unlimited support services. The students capitalize on the autonomy resulting from the informal environment to source multiple data from as many stakeholders as possible thereby gaining holistic perspective of their areas of interest, career and other value adding co curricular activities.The informal internet technologies have not only grown to become essential tools for reinforcing the formal learning activities but also critical requirements for developing social competence, interpersonal skills, and creativity.
\end{abstract}

\section{KEYWORDS}

Informal Internet tools, social media, digital technologies, holistic skills, knowledge acquisition.

\section{INTRODUCTION}

Web tools, mobile phone and desktop applications in virtually all communication devices have become an integral part of life of every young Saudi Arabian. The Internet presents a life-long learning opportunity for coping with the ever-changing needs of society. According to Greenhow, Sonnevend, and Agur, (2016), new technologies particularly social media are enabling highly rewarding experiences that were not possible in the past. For example, the digital-age students regularly engage in instant messaging, virtual consultations and real-time interactions with experts from multiple fields. In other words, the roles played by the social media and associated digital technologies have moved beyond online communication to revolutionizing the learning methodologies across the best universities and colleges in Saudi Arabia.

The informal Internet tools facilitate not only regular chats among peers but also support academic achievements and career advancement. As a result, an increasing number of University and college students are incorporating the knowledge acquired through the traditional networks into their coursework. Alqahtani, Issa, and Issias (2017) argue that internet technologies have become part and parcel of the vital academic programs in the mainstream institutions of higher learning in western countries.

On the other hand, although the education stakeholders in the geo-cultural such as the Middle Eastern nations are aware of the superior value associated with the technologies over the DOI: 10.5121/caij.2019.6302 
traditional learning techniques their adoption rates lags behind their peers. As Alim (2017) argues there is a lack of academic resources to explore the significance of Twitter and the other social platforms on the growth of education. This paper evaluates the importance of informal Internet tools in enhancing the quality of learning in Saudi Universities. In this case, the informal internet tools refer to all the web-based technologies contributing to the growth of e-learning but are initiated by the individual or a group of learners as opposed to institutions and authorized academicians (Mills \& Kraftl, 2014). The tools supplement the classroom activities and experiences but are not part of the official academic programs. According to Czerkawski (2016), the formal mechanisms are structured or predesigned to produce particular goals targeted by an instructor. In contrast, the informal learning is serendipitous and mostly occurs outside the classroom setting.

However, there is a slight difference between formal and informal Internet tools. As Czerkawski (2016) explains, scholars have noted that the students hardly enjoy optimum value in learning systems lacking appropriate structures for capturing gains from the informal networks. The advancement in technologies makes it difficult to separate the learning elements. For example, the difference between personal study activities and formal homework is becoming blurred due to the increase in internet-based tutorials. The Saudi Arabian colleges are capitalizing on the digital revolution to improve their pedagogical practices, learning delivery techniques and lecturerstudents relationships. The academicians are looking for ways for utilizing the social networking platforms in creating the world's best educational system. Therefore, there is a need to clarify the interactions between the learning tools and the roles of the stakeholders in delivering the best values to the students.

\section{The Use of Internet Tools in Saudi Arabian Universities}

Saudi Arabia is home to most of the digital applications users as compared to other Arab Countries. Alqahtani (2016) cites that there were 13 million social media users in the country by 2016. 51\% and $42 \%$ of the nation's population used Twitter and Facebook respectively. Saudi Arabians also accounted for $40 \%$ of the tweets that circulated in the Arab countries in 2014 (Alim, 2017). The commitment by governments to expand the information and communication infrastructures has been promoting the popularity of the advanced e-learning frameworks in the institutions of higher learning. The e-government platforms such as Yesser and Absher are fostering the adoption of the web-based tools in all the leading sectors of the economy. The Prince Mohammed bin Salman interest in ICT played a role in the rapid increase in the number of Internet users to 30 million or $91 \%$ by the beginning of 2018 (Abokhodair, Abbar, Vieweg, \& Mejova 2017). The top public officials have been utilizing the platforms to engage the public on critical national matters.

\section{RESEARCH QUESTIONS}

The research answered the following questions:-

- How do the informal Internet tools improve the learning outcomes, academic achievements and career advancement of the Saudi university students?

- What efforts are the Saudi Universities making to encourage their students to use the knowledge gathered via the informal Internet tools in enriching their career ambitions?

\section{LITERATURE REVIEW}

E-learning has kept pace with the changes in the socioeconomic and technological environment. Latchem (2014) argues that the impacts of the informal experiences in the education sector are 
evident through the 19th-century social experiments by Marxists and post-modernists. The scholars showed that advances in science, technology, and social organizations led to knowledge growth with the informal attributes contributing to a significant part of the know-how. The experiences at the family and community level reinforce the outcomes of the structured educational processes. According to Latchmen (2014), the experiments confirmed that formal learning programs alone are not adequate in responding to the ever-changing needs of modern society. For example, there was positive correlation between the unofficial or incidental learning activities and self-efficacy, self-esteem, wellbeing, and happiness.

The literature further shows that the levels of online education have been persistently increasing since it was launched in the 1980s (Benson and Morgan, 2014). The advancement of Internetbased technologies particularly the social media platforms such as YouTube, Myspace, Flickr, Facebook, and WhatsApp are revolutionizing the value derived from the e-learning. Chanchary and Islam (2014) found that the beneficiaries of the online educational facilities are increasing by about $25 \%$ annually. Long years of research have also shown that the informal tools are critical academic performance enhancers. Czerkawski (2016) argues that non-official tools are not only flexible but are student-centered thereby providing opportunities for perfecting interpersonal skills and other knowledge needed to excel in particular fields. The students join social media groups based on personal and professional interest.

The informal networks allow students to foster alliances with like-minded individuals as well as encourage the students to explore new ideas. Czerkawski (2016) found that curiosity-based experiences are good sources of ideas for dissertation topics and other class activities. Suitable examples include Face book that began as informal interaction platform between Mark Zuckerberg and his Harvard college mates and has transformed to become one of the world largest corporations. The innovation has spearheaded the development of twenty-first-century skills alongside peer social media platforms.

The users that combine the informal tools with the structured e-learning programs have been found to develop greater creativity, technological and research fluency as well as communication and problem skills. Lai and Smith's (2017) study confirmed the benefits of the diverse learning opportunities over the formal programs alone. The researchers examined how a group of New Zealand University employed the unstructured digital technologies to augment their academic performance. The learners can access over 300 informal learning websites with informative content. $90 \%$ of the respondents reported that the social networking platforms accounted for a significant portion of their formal learning.

Watching documentaries via YouTube and live chats with social media friend came in handy in undertaking class projects and dissertations. Trinder's (2017) study involving students from the Vienna University of Economics reached a similar conclusion. The online films and television series improved the learners listening skills, vocabulary and pronunciation. In Trinder's (2017) view, the Internet tools rank among the three best technologies for gaining communicative competence. $72 \%$ of the respondents deliberately used the informal resources to improve their language abilities.

\section{Methodology}

Systematic review enabled the researcher to gain up-to-date knowledge on the benefits of the informal Internet tools on the career and academic performance of the Saudi Arabian university students. Google Scholar provided scholarly publications on the various applications of the unstructured web technologies and applications in enhancing the outcome of the classroom programs in the leading institutions of higher learning across the country. The search terms 
included informal internet tools OR social networking tools AND formal education in Saudi Arabian Universities. A two-step inclusion and exclusion criteria were applied to select seven articles that best capture the impacts of the ever-changing web-based technologies in improving the quality of learning among active internet users. First, the review featured researches or studies conducted within the last five years. The timeframe ensured that only the current information was employed to provide evidence and formulate policies to promote the use of appropriate Internet tools in enhancing the experiences of the targeted Saudi Students.

Secondly, the relevance and applicability of the sources to the study population guided the selection criteria. The titles, abstract and main findings of the papers helped to identify articles that give accurate insights on the state of informal learning opportunities associated with the digital and related web-based technologies in Saudi Arabian institutions of higher learning. The reviewed papers explicitly explored the benefits as well as the challenges involved in incorporating the knowledge gathered from the social networking platforms into the formal educational programs. The in-text citations and references of the selected sources further helped in gathering additional evidence to support the main findings.

Data analysis involved cross verification of the results of all the reviewed publications. The researcher also statistically combined the outcomes of the studies. According to Charles-Smith et al. (2015), is a methodology for gathering the best pieces of evidence. The conclusions from multiple studies allow for the formation of consensus on the best solutions to the issue under investigation. As such, data triangulation was achieved by comparing and contrasting the advantages and shortcomings of the Internet tools gathered under different contexts by multiple scholars. The known benefits of internet technologies were used to develop a conceptual framework that guided the narrative synthesis of the selected sources. That is, evidence-based practices discussed in the literature review section reveal that embedding the informal Internet tools in e-learning environment is positively correlated to three values as depicted in the conceptual framework in figure one below.

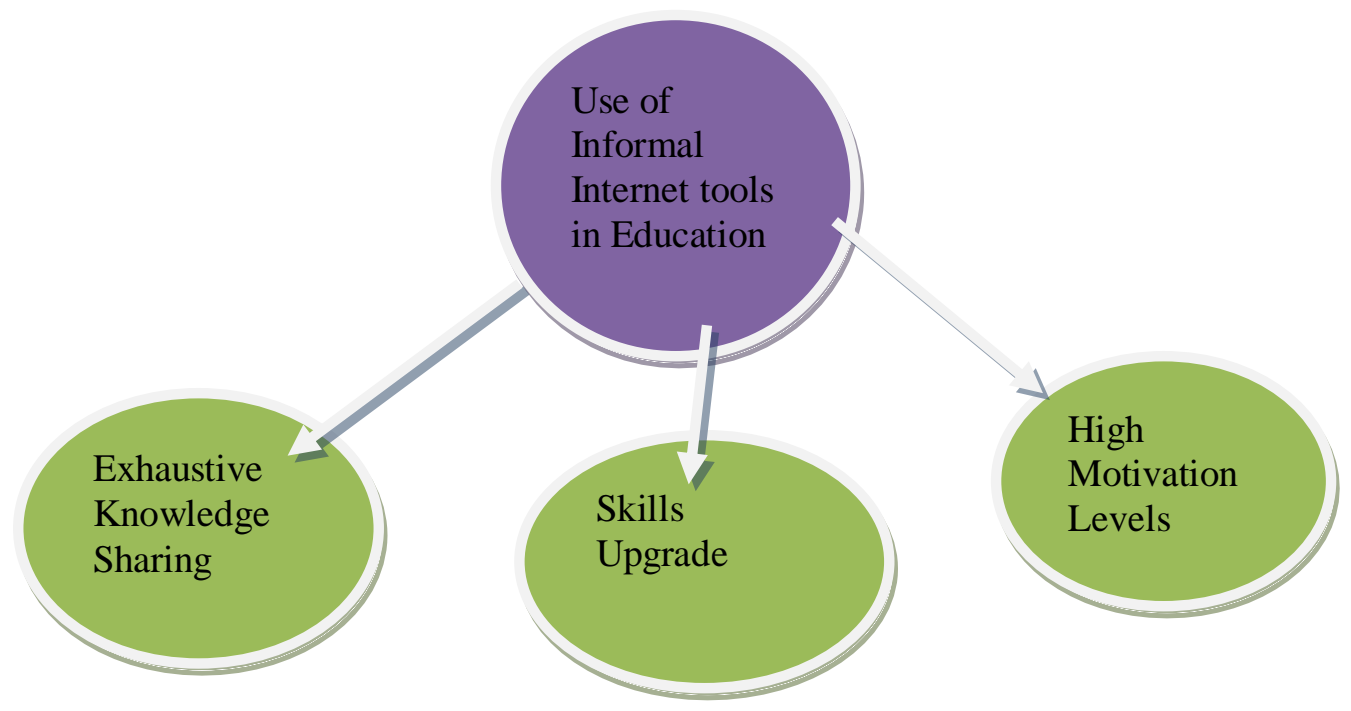

Figure 1: Conceptual Framework

Skills Upgrade: - the empowerments through the self initiated research and experiments are providing opportunities for internet users especially the postgraduate to climb the corporate ladder. The informal tools have been sources for career breakthroughs for innovative students like 
Mark Zuckerberg. The experts consider the big data analytics and associated digital technologies among the inventions of the century (Czerkawski, 2016).

Exhaustive Knowledge Sharing: - Individuals tend to share more information with the social media friends than through the formal networks (Trinder, 2017). The users establish online communities with fellow students to explore areas of interest. The informal environment allows the learners to ask personal questions as well as commit to learning new skills from each other. The tools create an open environment for exploring any personal idea or interest. That is, the learners are free to pursue knowledge that best suits their individual needs. LinkedIn and RSS are now popular data collection instruments while many students rely on social bookmarking for organizing, storing and sharing articles.

High Motivation Levels: - The self-direction leads to high performance. The students readily engage in self-generated tasks thereby replacing the boredom with excitement as well as eliminating the procrastination resulting from the formal learning programs. Maski (2015) found that the social dynamics create sense of belonging among platform subscribers including students that have never met or had face to face interaction with each other. For example, Wiki applications fosters collaborative learning as any registered individual can add content, criticize or give feedback on ideas generated by other community members. The ability to synthesize the knowledge prepares the learners for the complexities of the future complexities in the work environment.

\section{FINDINGS}

The search identified over 15,000 peer-reviewed journals, conference proceedings and dissertations on the roles played by the digital technologies in informal learning in Saudi Arabian universities. After moving the duplicates, sources that did not have full-text publications and screening the abstract vis-a-vis the paper objectives, the researcher identified seven sources that provided deep insights on the implications of the unstructured digital technologies on the quality of learning in the Saudi institutions of higher education. All the sources showed Saudi's commitment towards establishing a technology advanced education system. The objectives focused on the various values Saudi learning institutions deriving from the internet technologies. Similarly, the studies also used online questionnaires and investigated the impacts of multiple internet tools except for one source by Alim (2017) that focused on Twitter. For example, Alsuraihi et al. (2016) used an online questionnaire to determine the beliefs of the medical students on the significance of the digital tools on their performance. The results established the correlation of the social media and career growth, communication and collaboration skills. The researcher also examined the barriers to the use of informal Internet tools in education such as ethical barriers and lack of quality controls. Alhaj and Banafi (2015) also investigated the roles of social media on language development among medical students from Jazan University. In contrast, Alqahtani et al. (2017) explored the changing roles of social networking in university education as a formal and informal learning tool.

The studies further demonstrate the learning opportunities resulting from informal Internet tools. Kutbi (2015) investigated the perception of 25 female undergraduate students at a Saudi University towards informal digital tools. The researcher concentrated on why the young girls preferred social media over the structured e-learning technologies. Alim (2017) also critically evaluated the opinions and experiences on the growth of higher education due to the integration of Twitter with formal classroom activities. 


\section{Study Populations and Benefits gained from the Informal Internet Tools}

The participants comprised students from fields such as social sciences, languages, and education. Alsuraihi et al. (2016) investigated the effects of emails, Twitter, Facebook, YouTube, Wikis and other digital platforms on the experiences of 381 medical students from various Saudi Universities. The researchers found that integrating the social media with the regular teaching program enhanced learning among more than $90 \%$ of the study participants. While Alhaj and Banafi (2015) targeted the medical students with difficulties in memorizing the terminologies as they hardly communicate in English outside the classroom. They recruited 150 learners that spoke Arabic as their native language. Alhaj and Banafi (2015) found that the socialization process was critical for the acquisition of the vital skills required to excel in various academic fields. Majority of the respondent reported that the informal platforms increased their course achievement and grades. $74 \%$ strongly believed that collaboration via the digital platforms enhanced their knowledge on medical terminologies, $80 \%$ recorded increased creativity, and $90 \%$ agreed that acquiring new content was more exciting through the social media than the formal channels.

Kutbi (2015) also employed online questionnaires and Skype phone interviews to collect the views of 25 female students from Abdul Aziz University. The young girls relied on social media for academic support services such as mentoring, tutoring and coaching. First, their lecturer created a Twitter journal to access the students' feedback. The students then posted and reacted to the week's unit as well as sought for clarification on the concepts that were not clear to them. Similarly, the students had an official Facebook account where they accessed videos illustrating the important class concepts. The instructor tagged all his students whenever he posted new content. Like the learners in Alhaj and Banafi (2015) and Alsuraihi et al. (2016) case, Kutbi's (2015) study participants enjoyed opportunities for reviewing the class concepts from multiple perspectives. That is, the instructor introduced guidelines to ensure seamless coordination among the class members. The students that missed classes viewed the live classroom session via blackboard collaborate. The lecturer further retweeted informative and creative posts. However, $12 \%$ of the respondents had negative attitudes towards the informal internet tool. The students argued against incorporation of the social media into the regular class work. On the other hand, $80 \%$ of the participants were not only satisfied with the integrated learning platforms but also wished that they could employ the digital technologies in all their courses (Kutbi, 2015).

Alim (2017) recruited the study participants via SurveyGizmo from all the top universities in the country. Although the questionnaire reached about 3,000 academicians, only 100 provided the targeted information. The responses offered profound insight into the implications of Twitter on university education. The respondents comprised experts from multiple disciplines. Alim (2017) concluded that both the formal and informal use of digital tools had proliferated in the past decade. For example, even the techno-savvy students like those undertaking operating systems course were reluctant to create a twitter account in 2008 . However, the country is currently one of the leading social media users controlling more than $40 \%$ of the tweets originating from the Arab nations. Virtually all the university students are relying on the platform in accessing support from lecturers and course mates and passing important information such as campus events reminders. The informal activities such as making hashtags, scheduling personal lectures and study groups came in handy in enhancing the learning outcomes.

However, distractions from the online friends pose threats to high academic performance among many Saudi Arabian university students. According to Alami (2017), almost all the respondents argued that the active Twitter users lost valuable time chatting with friends on matters that did not have positive impacts on their careers. Frequent tweets also switched the users' attention to trending topics that might not be related to the ongoing class activity. The researcher recommends 
that lecturers need to have access to evidenced-based practices for managing such issues that are interesting to their students but are not much useful to their academic life.

\section{DisCUSSIONS}

The review reveals that informal Internet tools will continue to controls most of the breakthroughs in the education sector and career-making opportunities in the foreseeable future. The appropriate use of social media and related digital technologies is a leading determinant of success for the university students in their studies as well as in the corporate world. $87.7 \%$ of the 381 interviewed by Alsuraihi et al. (2016) agreed that social media was instrumental in their learning. 93.8\% used YouTube, Facebook, Twitter, and Wikis regularly in their studies. These included communicating with their tutors and exchanging ideas with their peers from different institutions. Similarly, more than $91 \%$ of students in the survey by Alqahtani et al. (2017) revealed that their social media friends helped them to focus on the crucial areas while revising for the continuous assessment and other exams. The informal tools made it easier for medical students to search for specific topics, explore a variety of example on a particular concept.

The best learning institutions are turning the online platforms from time-wasting tool or distracters into sources of motivation (Lai and Smith, 2017). An increasing number of Saudi Arabian University stakeholders have developed networks with fellow students, mentors, tutors, coaches and other experts in their fields thereby enabling them to attain high grades, make better career decisions and excel in their workplaces. Alim (2017) found that Twitter increased class attendance, discussion and one on one interaction with the college mates. Lecturers rely on Twitter to keep posted on the latest trend in education and research. The updated knowledge is then integrated into classroom activities. Twitter has enabled thousands of Saudi Arabians to collaborate on big projects, grow ideas, convert proposals into scientific outputs and suggest recommendations for future research. The students also use the tools to provide feedback about the class work and learning materials.

The informal Internet tools impact significantly on three learning areas namely attitude, collaboration and access to all the necessary support needed to develop holistic skills and knowledge in all the disciplines.

\section{Internet Tools as Sources of Motivation}

The empirical data presents sufficient evidence that every learning institution must balance the formal class programs with the continually evolving web-based technologies in order to capture the attention of the current generation of students. Alqahtani et al. (2017) confirm the findings of Alhaji and Banafi (2015) that higher education will remain the game changer as far as adoption of Internet tools is concerned. This is because the current generation of university students is digital natives or those born from 1980. The learners are brought up in a networked society where most of the decisions are influenced by the mainstream media. The success rates, therefore, depend on how best the lecturers incorporate the digital content into the learning activities. The best educational system establishes comprehensive programs that best suit the lifestyles, interests and well being of the students. The lecturers with the vast knowledge and experience on the emerging digital technologies are in high demand not only in Saudi Arabia but also in the world's leading universities. The techno-savvy teaching staffs are involved in the delivery of the online courses that in most cases target students that are able to succeed in the programs both through the support from the tutors as well as self-regulated efforts.

The effective use of social media in the degree courses is positively correlated with a university's ability to sustain the interests of the students. Inadequate opportunities for integrating the social 
media content into formal learning process promote the adverse effects of the digital technologies on education. The studies blame the misuse of social media on the lack of access to the right networks. In contrast, connections with the right individuals enable the students to substitute the time spent on streaming videos and entertainment with the urge to read for pleasure, build on knowledge acquired in class and pursue other value-adding activities.

\section{Access to Appropriate Support and Academic Networks}

The evidenced-based practices indicate that informal Internet techniques provide a powerful tool for bringing the individual to work together towards achieving the best levels of education. In fact, all the sources advocates for blending of the class work and collaborations with the online communities in pursuing areas of interest, developing new knowledge and linking with the industry. A growing number of lecturers capitalize on the informal web-based platforms to create exciting lessons plans that cater for the diverse needs of the students. Chanchary and Islam (2014) found that the technologies made it easier for the Saudi Arabian lecturers to assess their student 's interests, how well the learners worked together, respect each other's viewpoints and manage conflict while undertaking joint tasks. Twitter particularly strengthened the lecturer-student relationships as some professors utilized the channel to mentor the young learners. In Alsuraihi et al.'s (2016) view the self-directed platforms presented better content and opportunities for accessing integrated information and interacting with experts than the formal sources such as textbooks and e-Medicine databases. However, the lack of ethical guidelines to regulate such informal learning processes poses a threat to the users. There are high risks of conflicts due to the close relationships as the topics of discussion can quickly change to personal matters.

\section{Skills Upgrade}

The Internet is a mandatory training requirement for the future workforce. As Raish and Rimland (2016) observed, the best employers rank the quality of an education system based on its ability to produce graduates with holistic skills set. The reviewed studies also concur that the informal platforms are fast replacing the traditional learning approaches in preparing the students for the future work responsibilities (Alhaji and Banafi 2015; Alsuraihi et al., 2016; Alqahtani et al., 2017). According to the researchers, students that balance the informal and formal Internet tools gained multiple skills giving them a competitive advantage in the labor markets. Such learners have the abilities to create, share and organize digital content, and critique other users' input. Therefore, excelling in the future corporate world needs highly flexible individuals with abilities to utilize the next generation technologies in delivering optimum results in their companies.

\section{CONCLUSION}

The advent of Internet technologies provided powerful means for supporting excellence at all levels of education. Saudi Arabians now enjoy support from all over the world as they progress in their education and join the corporate world. The ongoing studies document the benefits of new learning techniques. The researchers concur that the advantages of the informal tools include sharing of experiences, collaboration in class projects, moral support and ease of accessing innovative ideas. Learners combining the class programs with the self-directed platforms have the upper hand in advancing in their careers than their conservative counterparts that are reluctant to explore the digital networks.

\section{RECOMMENDATIONS}

The Saudi Arabian Universities should update their policies to guide the students on the use of the informal Internet tools in their careers. Comprehensive ethical frameworks would go a long way 
in enhancing the country's achievements as far as digital learning opportunities are concerned. Kutbi's (2015) study showed that informal Internet tools present the best platforms for addressing the adverse outcomes of social media on education. Experts concern that only a few current generations of students can write error-free original essays can be solved by introducing social media classes alongside the regular lessons. The students' in the studied Abdul Aziz literature class had firsthand experience on the effects of short messages and social media chats on grammar, punctuation and communication skills. The instructor reviewed the posts, corrected the errors and challenged the students to improve their literary skills.

On the other hand, their peers from the other courses that did not access guidance were more likely to be influenced by the grammatical mistakes such as the shorthand, abbreviation and incomplete sentences characterizing most social media posts (Abokhodair et al., 2017). Consequently, all the Saudi Arabian Universities should move with speed in establishing proactive measures for promoting responsible culture transfer among the active social media users. The structures should be tied to the risks associated with the increased influence of the emerging technologies on education growth. Abokhodair et al. (2017) advise that every course should have omnichannel frameworks for motivating the learners to focus their attention on the academic, personal and career developmental content. In other words, having interconnected class accounts in all the popular social media and digital platform increases the students' chances of developing the best networks and support towards achieving excellence in their careers.

\section{REFERENCES}

[1] Abokhodair, N., Abbar, S., Vieweg, S. \& Mejova, Y. (2017). Privacy and social media use in the Arabian Gulf Saudi Arabain \& Qatari Traditional values in the digital world. The Journal of Web Science, 3(1), pp. $1-13$.

[2] Alhaj, A. A., \& Banafi, N. (2015). The impact of social networks on EFL medical students' academic performance at Jazan University. International Conference the Fauture of Education.

[3] Alim, S. (2017). Understanding the use of Twitter for teaching purposes in Saudi Arabian Universities. International Journal of Web-based Learning and Teaching Technologies, 12(3), 1 -20.

[4] Alqahtani, S., Issa, T., Issa, T \& Isais, P. (2017). Saudi Arabian studtents' attitudes to and perceptions of social networking for educational purposes. The Ninth International Conference on Mobile, Hybrid, and On-line Learning eLmL 2017: Nice, France.

[5] Alqahtani,S. (2016). Social networking framework for universities in Saudi Arabia. International Conference. Retrieved from https://files.eric.ed.gov/fulltext/ED571569.pdf

[6] Alsuraihi, A. K., Almaqati, A. S., Abughanim, S. A., \& Jastaniah, N. A. (2016). Use of social media in education among medical students in Saudi Arabia. Korean Journal of Medical Education, 28(4), 343-354

[7] Benson, V., \& Morgan, S. J. (2014). Cutting-edge technologies and social media use in higher education. Hershey PA Information: IGI Global.

[8] Charles-Smith, L. E., Reynolds, T. L., Cameron, M. A., Conway, M., Lau, E. H., Olsen, J. M., ... \& Corley, C. D. (2015). Using social media for actionable disease surveillance and outbreak management: a systematic literature review. PloS One, 10(10), e0139701.

[9] Greenhow, C., Sonnevend, J., \& Agur, C. (2016). Education and social media: Toward a digital future. Cambridge: The MIT Press. 
Computer Applications: An International Journal (CAIJ), Vol.6, No.1/2/3, August 2019

[10] Kutbi, A. (2015). How undergraduate female students in the Kingdom of Saudi Arabia perceive social media as a learning tool: An exploratory study. Windsor: University of Windsor Press.

[11] Lai, K. \& Smith, L. (2017). Tertiary students' understandings and practices of informal learning: A New Zealand Case Study. Australian Journal of Educational Technology 33(2) 115 -127.

[12] Latchem, C. (2014). Informal learning and non-formal education for development. Journal of Learning for Development 1(1), 1 -14.

[13] Mills, S., \& Kraftl, P. (2014). Informal education, childhood and youth: Geographies, histories, practices. Palgrave Macmillan.

[14] Raish, V., \& Rimland, E. (2016). Employer perceptions of critical information literacy skills and digital badges. College \& Research Libraries, 77(1), 87-113.

[15] Trinder, R. (2017). Informal and deliberate learning with new technologies. ELT Journal 71(40), 401 -412 .

\section{AUTHORS}

Abdullah Alenezi, Dr. of Education, is Assistant Professor in the Educational Technology Department, Faculty of Education, Northern Borders University, Saudi Arabia (email: abdullah.a.alenezi@nbu.edu.sa). His major areas of interest and expertise are: organizational change, teaching and learning outcomes arising from uses of leading-edge technologies, implementation and management of leading-edge technologies at the local authority and individual institution levels, uses and impacts of technologies and technology-based resources in formal educational environments, distance learning and training, and technology integration in the Saudi context.

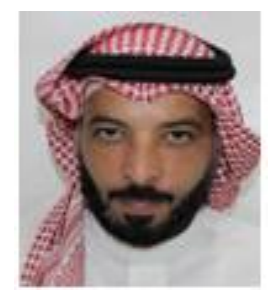

